\title{
Factors of Exclusive Breastfeeding Among Mothers of Children Aged 0-6 Months in Brazzaville: The Case of Talangai Health District in 2018
}

\author{
Arkadit Jeandria Nkodia ${ }^{1, ~ *, ~ E u l d ~ N o e l i e n ~ I v i g a ~ D o u f o u i l o u ~}{ }^{2}$, Hermann Brunel Ngatseke', \\ Gertrude Ndeko' ${ }^{2}$, Nicodeme Okobo ${ }^{2}$, Ange Clauvel Niama ${ }^{1}$, Gilbert Ndziessi' ${ }^{1}$, Ange Antoine Abena ${ }^{3}$ \\ ${ }^{1}$ Department of Public Health, Faculty of Health Sciences, Marien Ngouabi University, Brazzaville, Republic of the Congo \\ ${ }^{2}$ Department of Population and Development, Faculty of economic Sciences, Marien Ngouabi University, Brazzaville, Republic of the Congo \\ ${ }^{3}$ Laboratory of Biochemistry and Pharmacology, Faculty of Health Sciences, Marien Ngouabi University, Brazzaville, Republic of the Congo
}

Email address:

arkaditn@gmail.com (A. J. Nkodia)

${ }^{*}$ Corresponding author

\section{To cite this article:}

Arkadit Jeandria Nkodia, Euld Noelien Iviga Doufouilou, Hermann Brunel Ngatseke, Gertrude Ndeko, Nicodeme Okobo, Ange Clauvel Niama, Gilbert Ndziessi, Ange Antoine Abena. Factors of Exclusive Breastfeeding Among Mothers of Children Aged 0-6 Months in Brazzaville: The Case of Talangai Health District in 2018. European Journal of Preventive Medicine. Vol. 9, No. 2, 2021, pp. 71-74.

doi: 10.11648/j.ejpm.20210902.17

Received: March 27, 2021; Accepted: April 12, 2021; Published: April 26, 2021

\begin{abstract}
Background: Poor nutrition during a child's early years can have irreversible consequences for their health. The objective of our study was to identify the factors associated with exclusive breastfeeding (EBF) among mothers of children 0 to 6 months in the Talangai Health District (THD). Methods: This was a cross-sectional analytical study carried out from April 17 to July 17, 2018 in the THD. Our study involved 256 mothers of children 0-6 months old in THD Health Facilities (HF). The logistic regression was used to identify factors associated with EBF. Epi Info software version 3.5.4 was used for data entry and the STATA 14 program for data analysis. Results: The average age of the mothers was 27 years old. More than half of the mothers were between $15-25$ years old or $53.9 \%$. The majority of mothers were housewives $(63.3 \%)$ and more than half had a secondary education $(60.9 \%)$. There was a predominance of separated or divorced mothers, $71.1 \%$ and the third rank of the child, $38.3 \%$. The prevalence of exclusive breastfeeding was $36.7 \%$. Being a middle or senior manager was significantly associated with breastfeeding, AOR $=2.9[1.5,5.3]$, p-value $<0.0001$. Conclusion: The practice of breastfeeding among mothers of children aged 0 to 6 months is still low and few determinants influence it. In order to promote the health of mothers and children, efforts still need to be made to strengthen breastfeeding for mothers of children 0-6 months.
\end{abstract}

Keywords: Breastfeeding, Factors, Mothers, Children, Health District

\section{Introduction}

Worldwide, 77 million newborns are not breastfed during the first hour of their life [1]. Breastfeeding is one of the most effective ways to maintain the health and ensure the survival of the child [2]. Only about $25 \%$ of babies are exclusively breastfed until the age of six months in developing countries [3]. Poor nutrition during a child's early years can have irreversible consequences for their health [4]. Exclusive breastfeeding decreases infant mortality from common childhood illnesses such as diarrhea or lung disease and accelerates recovery from illness [5]. Children who are breastfed during the first few months are at least six times more likely to survive than children who are not breastfed [6]. Globally, it is estimated that only $38 \%$ of infants are exclusively breastfed for the first six months [7]. Studies have shown that EBF is associated with several determinants such as demographic, socioeconomic and sociocultural factors [8]. However, in Congo little data is available on factors associated with EBF. This is how the aim of this study is to identify the factors associated with EBF in mothers of children 0-6 months old in the Talangai Health District. 


\section{Methodology}

\subsection{Study Design}

This was a cross-sectional, analytical study carried out over a period of 3 months, from April 17 to July 17, 2018 in the Talangai Health District (THD). The target population was made up of mothers of children aged 0 to 6 months admitted to Health Facility (HF) of the THD.

\subsection{Sampling}

We carried out a stratified survey. The strata were made up of the 4 HF of the THD. The sample size was calculated by the formula of Daniel Schwartz.

$\mathrm{N} \geq U \alpha^{2} \frac{P(1-P)}{\Delta^{2}} \mathrm{~N}=$ Sample size;

Precision $\Delta=5 \%$, prevalence $(\mathrm{p})=21 \%$ (DHS-2011-2012);

$\mathrm{N} \geq 255$ mothers of children $0-6$ months

Each stratum was proportional to the attendance of each HF. The distribution of the sample was made as follows:

Marien Ngouabi Health Facility, 80 mothers of children;

Ma Mbouale Health Facility, 68 mothers of children; Intendance Health Facility, 62 mothers of children; Fleuve Congo Health Facility, 46 mothers of children; Inclusion: Were included in our study, mothers of children aged 0 to 6 months received in preschool consultation in the HHs of the THD and agreeing to participate in the survey.

Non-inclusion: Mothers whose children were not within the 0-6-month age range or were in the range but refused to participate in our survey.

\subsection{Data Collection}

Data were collected prospectively by interviewing mothers of children using a questionnaire.

\subsection{Data Analysis}

Logistic regression was used to identify factors associated with EBF. Our variable of interest was the practice of exclusive breastfeeding coded $1=$ Yes.

Data were entered using EPI INFO software.

The STATA 14 program was used for data analysis. First, a uni-varied analysis between EBF and the independent variables was performed.

Then, variables with an associated OR and a degree of significance of $\mathrm{p}<0.05$ were retained for multivariate analysis. Multiple logistic regression by the block entry method was used in multivariate analysis.

\section{Results}

\subsection{Sociodemographic Characteristics of Mothers}

A total of 256 mothers of children 0-6 months old were included in our study. The mothers' average age was 27 . More than half of the mothers were 26 years old. The most repeating mothers' age was 23 . More than $25 \%$ of mothers were 22 years old or less, and more than $75 \%$ were 30 years old or less. The smallest mother was 15 and the older was 44 .

The majority of mothers were aged $15-25$, or $53.9 \%$. More than half of the mothers were housewives, ie $63.9 \%$, and the most repeated level of education was secondary level, ie $60.9 \%$.

Most mothers were divorced or lived alone or $71.1 \%$ and for over $38.8 \%$ of mothers in this study, this was their third child. The socio-demographic characteristics of the mothers have been described in Table 1.

Table 1. Sociodemographic characteristics of mothers $(n=256)$.

\begin{tabular}{lll}
\hline Variables & Values & \% \\
\hline Age of Women (years) & & \\
Mean \pm SD & $27 \pm 6$ & \\
Median [Q1, Q3] & $26[22,30]$ & \\
Mode & 23 & \\
Min, Max & 15,44 & \\
Age group of Women (years) & & \\
15-25 & 138 & 53.9 \\
$26-35$ & 100 & 39.1 \\
$36-45$ & 18 & 7.0 \\
Professional status & & \\
Labour & 32 & 12.5 \\
Household & 162 & 63.3 \\
Middle/Senior Manager & 62 & 24.2 \\
Level of education & & \\
Primary & 15 & 5.9 \\
Secondary & 156 & 60.9 \\
Post-Secondary & 85 & 33.2 \\
Marital status & & \\
Single & 16 & 6.3 \\
In a relationship & 58 & 22.7 \\
Divorced/separate & 182 & 71.1 \\
Child's rank & & \\
$1^{\text {st }}$ child & 93 & 36.3 \\
$2^{\text {nd }}$ child & 65 & 25.4 \\
$3^{\text {rd }}$ child or more & 98 & 38.3 \\
\hline
\end{tabular}

\subsection{Prevalence of Exclusive Breastfeeding (Percentage)}

Figure one shows that the prevalence of EBF was $36.7 \%$.

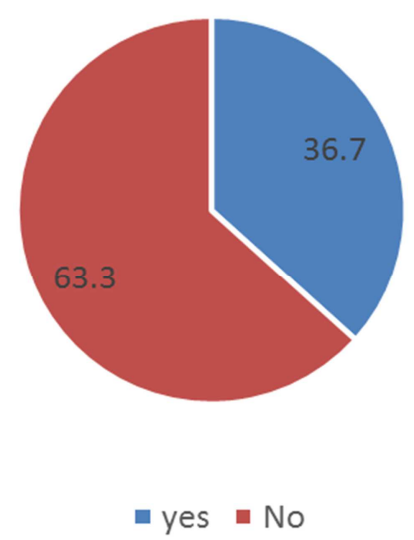

Figure 1. Prevalence of exclusive breastfeeding among mothers of infants 0-6 months of age in Talangai Health District $(n=256)$.

\subsection{Factors Associated with Exclusive Breastfeeding}

In univariate analysis, we found that two factors were 
significantly associated with the practice of exclusive breastfeeding.

These included professional status and marital status, the odds ratio brut of which were respectively $2.9[1.5,5.3]$ and $3.0[1.0,8.8]$.

After adjustment, professional status was the only associated factor. Referring to the results of the multivariate logistic regression, we found that occupational status was the factor strongly associated with the practice of exclusive breastfeeding. In fact, mothers of middle or senior professional status were significantly associated with the practice of exclusive breastfeeding than housewives or workers $(\mathrm{AOR}=3.1 ; 95 \% \mathrm{CI}: 1.5,5.3)$, P-value $<0.0001$

Table 2. Factors associated with the practice of exclusive breastfeeding in mothers of infants 0 to 6 months old at DST, ( $n=256$ ).

\begin{tabular}{|c|c|c|c|c|}
\hline \multirow{2}{*}{ Independent variable } & \multicolumn{2}{|c|}{ Univariate analysis } & \multicolumn{2}{|c|}{ Multivariate analysis } \\
\hline & bOR [95\%CI] & P-value & aOR $[95 \%]$ & P-value \\
\hline \multicolumn{5}{|l|}{ Ag of Women (years) } \\
\hline $15-19$ & 1 & Ref & & \\
\hline $20-24$ & $0.7[0.4,1.2]$ & 0.309 & & \\
\hline $25-29$ & $1.6[0.5,4.2]$ & 0.348 & & \\
\hline \multicolumn{5}{|l|}{ Professional status } \\
\hline Labour & $0.8[0.3,2.0]$ & 0.758 & $0.8[0.3,1.9]$ & 0.691 \\
\hline Middle/Senior manager & $2.9[1.5,5.3]$ & 0.001 & $3.1 *[1.6,5.7]$ & 0.0001 \\
\hline \multicolumn{5}{|l|}{ Level of education } \\
\hline Primary & 1 & Ref & & \\
\hline Secondary & $0.8[0.2,2.5]$ & 0.716 & & \\
\hline Post-secondary & $2.1[0.6,6.8]$ & 0.195 & & \\
\hline Dicorced/separate & 1 & Ref & 1 & \\
\hline Single & $3.0[1.0,8.8]$ & 0.037 & $0.2[0.07,0.8]$ & 0.021 \\
\hline In relationship & $0.9[0.5,1.8]$ & 0.924 & $0.2[0.09,0.7]$ & 0.017 \\
\hline \multicolumn{5}{|l|}{ Child's rank } \\
\hline $1^{\text {st }}$ Child & 1 & Ref & & \\
\hline $2^{\text {nd }}$ Child & $0.8[0.4-1.6]$ & 0.880 & & \\
\hline $3^{\text {rd }}$ Child or more & $0.3[0.1,0.6]$ & 0.357 & & \\
\hline
\end{tabular}

\section{Discussion}

This study determined the prevalence of exclusive breastfeeding in the Talangai Health District as well as the factors associated with this practice. Our study shows that its prevalence is $36.7 \%$. Whether a mother was a middle or senior manager was significantly associated with the practice of exclusive breastfeeding than being a housewife or a worker. Regarding socio-demographic characteristics, the average age of mothers is 26.5 years. The average age of mothers of children in our study is slightly higher than that found by Diawara YD in Mali, an average of 25.3 years [9]. In contrast, it was approximately similar to that found by Traore et al in Mali [10]. We found a standard deviation of \pm 6 years in our study; this standard deviation is slightly higher than that found by Amed Coulibaly in Ivory Coast, i.e. a standard deviation of 5.05 years [11]. The prevalence of exclusive breastfeeding in our study is slightly higher than that found at the national level, ie $21 \%$ (reference, DHS 2011-2012) and clearly low at the global prevalence, ie 43\%. Our prevalence of exclusive breastfeeding is also lower than that found by Tilksew A and all in Ethiopia, i.e. 57.3\% [12] and 51.4 by Salim and all in Malawi [13] against $47.3 \%$ by Bisrat Zeleke and all [14]. This difference could be explained by an improvement over time in the practice of exclusive breastfeeding among mothers of children aged 0 to 6 months in Brazzaville. The last DHS 2011-2012 survey was six years old from our study. As for this considerable duration, we can understand that the practice of exclusive breastfeeding has changed a lot over time; creating quite significant disparities compared to the last prevalence, founded in 2012 at the national level. Furthermore, professional status was the only factor associated with the practice of exclusive breastfeeding. In our study, mothers of middle and senior professional status were significantly associated with the practice of exclusive breastfeeding than mothers of professional homemaking status. Our results corroborate with those reported by Noir-homme $F$ and all [15]. One of the limitations of our study is characterized by the fact that our research did not highlight a large number of variables associated with AME which have been described in the literature, this is due to the fact that our study $\mathrm{s}$ " is carried out in health centers and not in a household population.

\section{Conclusion}

The results of our research confirm the low prevalence of exclusive breastfeeding among mothers of children aged 0-6 months in Talangai Health District. In addition, the practice of EBF is not associated with the mother's age, educational level or the child's rank. Communication for behavior change 
should be implement in the Health District to improve adherence to the practice of EBF among mothers of children.

\section{References}

[1] Worldwide, 77 million newborns are not breastfed for the first hour of their life [Internet]. UNICEF France. 2016 [cited 2019 Dec 16]. Available at: https://www.unicef.fr/contenu/espace-medias/77-millions-de-n ouveaux-nes-ne-sont-pas-nourris-au-sein-durant-leur-premiere -heure-de -life.

[2] WHO $\mid 10$ facts about breastfeeding [Internet]. WHO. [cited 16 Dec 2019]. Available at: http://www.who.int/features/factfiles/breastfeeding/fr/.

[3] Hall J. Effective community-based interventions to improve exclusive breast-feeding at four to six months in low- and low-middle-income countries: a systematic review of randomized controlled trials. Midwifery. 2011 Aug; 27 (4): 497-502.

[4] Exclusive Breastfeeding: An Absolute Necessity [Internet]. UNICEF France. 2013 [cited March 17, 2021]. Available at https://www.unicef.fr/article/l-allaitement-maternel-exclusif-u ne-necessite-absolue.

[5] WHO | Exclusive breastfeeding [Internet]. WHO. [cited 16 Dec 2019]. Available at: https://www.who.int/nutrition/topics/exclusive_breastfeeding/fr/.

[6] Breastfeeding [Internet]. UNICEF. [cited 16 Dec 2019]. Available at: https://www.unicef.org/french/nutrition/index_24824.html.

[7] WHO | Breastfeeding: Only one in five countries fully comply with the WHO Code for Infant Formula [Internet]. WHO. [cited 16 Dec 2019]. Available at: https://www.who.int/mediacentre/news/releases/2013/world_b reastfeeding_week_20130730/fr/.

[8] Mututho LN, Kiboi WK, Mucheru PK. Factors associated with exclusive breastfeeding in Kenya: a systematic review. Int J Community Med Public Health [Internet]. 2017 Nov 23 [cited 2019 Dec 10]; 4 (12): 4358-62. Available at: https://www.ijcmph.com/index.php/ijcmph/article/view/1983.

[9] Diawara YD. Study of the factors associated with exclusive breastfeeding among mothers of infants aged 0 to 6 months in Beleko in the Sanitary District of fana '. 2015 [cited 22 Dec 2020]; Available

https://library.adhl.africa/handle/123456789/8897.

[10] Traore M, Sangho H, Diagne MC, Faye A, Sidibé A, Koné K, et al. Factors associated with exclusive breastfeeding among mothers of 24-month-old infants in Bamako. Public Health (Bucur) [Internet]. May 27, 2014 [cited Dec 22, 2020]; Vol. 26 (2): 259-65. Available at: https://www.cairn.info/revue-sante-publique-2014-2-page-259 .htm.

[11] Coulibaly A, Tano OA, Vroh JBB, Traore Y, Dagnan NS. Socio-professional factors and practice of exclusive breastfeeding by first-time mothers in Abidjan (Ivory Coast). Public Health (Bucur) [Internet]. 8 Oct 2014 [cited 22 Dec 2020]; Vol. 26 (4): 555-62. Available at: https://www.cairn.info/revue-sante-publique-2014-4-page-555 .htm.

[12] Ayalew T. Exclusive breastfeeding practice and associated factors among first-time mothers in Bahir Dar city, North West Ethiopia: A community based cross sectional study. Heliyon [Internet]. 1 sept 2020 [cited March 9 2021]; 6 (9): e04732. Available https://www.sciencedirect.com/science/article/pii/S240584402 0315759.

[13] Salim YM, Stones W. Determinants of exclusive breastfeeding in infants of six months and below in Malawi: a cross sectional study. BMC Pregnancy Childbirth [Internet]. August 172020 [cited March 9 2021]; 20 (1): 472. Available at: https://doi.org/10.1186/s12884-020-03160-y.

[14] Factors Associated with Early Initiation and Exclusive Breastfeeding Practices among Mothers of Infant's Age Less Than 6 Months - MedCrave online [Internet]. [Cited March 9 2021]. Available at: https://medcraveonline.com/JPNC/factors-associated-with-earl $y$-initiation-and-exclusive-breastfeeding-practices-among-mot hers-of-infantrsquos-age-less-than-6-months.html.

[15] Noirhomme-Renard F, Noirhomme Q. Factors associated with prolonged breastfeeding beyond three months: a review of the literature. J Pediatrics Childcare [Internet]. 2009 May [cited 2020 Dec 22]; 22 (3): 112-20. Available at: https://linkinghub.elsevier.com/retrieve/pii/S09877983090005 162056-2081. 